Article

\title{
The Influence of Brand Image on Brand Extension Evaluation: Design of the Living Intention Service Model and Brand Positioning of a Retirement Community
}

\author{
Tsai-Hsuan Tsai ${ }^{1,2,3,4,5,+}$, Alice M. K. Wong ${ }^{3,5,+}$, Hsiu-Feng Lee ${ }^{2}$ and Kevin C. Tseng ${ }^{5,6, *(1)}$ \\ 1 Department of Industrial Design, Chang Gung University, Taoyuan 33302, Taiwan; ttsai@mail.cgu.edu.tw \\ 2 Graduate Institute of Business and Management, Chang Gung University, Taoyuan 33302, Taiwan; \\ service@pddlab.org \\ 3 Department of Physical Medicine and Rehabilitation, Chang Gung Memorial Hospital, \\ Taoyuan 33305, Taiwan; walice@cgmh.org.tw \\ 4 Department of Visual Communication Design, Ming-Chi University of Technology, \\ New Taipei City 24301, Taiwan \\ 5 Product Design and Development Laboratory, Taoyuan 33343, Taiwan \\ 6 Department of Industrial Design, National Taipei University of Technology, Taipei 10608, Taiwan \\ * Correspondence: ktseng@pddlab.org \\ + These authors contributed equally to this work.
}

Received: 10 August 2020; Accepted: 2 September 2020; Published: 11 September 2020

check for updates

\begin{abstract}
The proportion of the elderly in Taiwan's population has been increasing in recent years. In the context of ageing and a low birth rate, retirement care for the elderly has become a serious challenge but remains underresearched. Choosing a retirement community that meets the needs of the elderly by considering their health and leisure activities and providing housing has become an important ageing-related topic. Therefore, this study aims to investigate whether the living intention of the elderly when choosing a retirement community is affected by brand attachment, high partner quality, brand trust and commitment, and brand self-congruence. A living intention service model is proposed and an empirical study is conducted with 101 random residents of Chang Gung Health and Culture Village (CGHCV) to measure the constructs proposed in the model. The results show that self-congruence and partner quality did not have a significant impact on the elderly's brand trust and commitment, likely because when choosing their last residence, unlike when buying general consumer products, the elderly attach more importance to healthcare brands, which in turn affects their living intention.
\end{abstract}

Keywords: brand image; brand extension; elderly; retirement community; service model

\section{Introduction}

The proportion of the elderly in Taiwan's population has been increasing in recent years, indicating that Taiwan has an ageing society. With ageing and a low birth rate, retirement care for the elderly has become a serious challenge but remains underresearched. The retirement community represents a new living arrangement that is a long-term care option allowing independent older adults who wish to age in place to do so [1,2]. Choosing a retirement community that meets the needs of the elderly by considering their health and leisure activities and providing housing has become an important ageing-related topic. For the elderly, when choosing a retirement community, brand attachment, brand services [3], self-congruence and perception of partner quality affect their brand trust and commitment, while gender, children, etc., play a regulatory (mediating) role in self-congruence, partner quality, 
brand trust and commitment. Investigating elderly consumers' behaviour when choosing a retirement community and their final choices for retirement community care is very important for studies on ageing societies and retirement community brand construction. However, the brand attachment of the elderly has long been overlooked. In this study, we propose a change in brand relationships toward the emotional aspect based on socioemotional selectivity theory (SST) [4]. The elderly are prone to make judgments on a brand based on trust; therefore, the role that brand plays in partner quality is highly important. Elderly consumers' views and perceptions of a brand can be described from the perspective of brand attachment processes. Brand attachment is a brand relationship-based concept and considers the link between the elderly and the brand [5] or more generally the emotional bond between people and a brand [6,7]. Therefore, in this study, we propose that living intention is likely the outcome of elderly consumers' brand attachment process, which can be represented by the relations among four factors: self-congruence, partner quality [7], trust and brand commitment [8,9].

Moreover, people's life experiences, differences in opportunities, chronic work stress, level of education, closeness of interpersonal relationships, and social status place each individual on a different track, affecting daily functions, health and life expectancy $[10,11]$. The ageing of the population is an inevitable trend; therefore, it is necessary to create a living environment suitable for the elderly so that they can maintain their daily functions with dignity as their physical functions gradually decline [12]. The ageing population and lifestyle changes (due to physical ageing) make it necessary to consider providing a new supportive housing environment to promote the independence and quality of life of the elderly. The objective of living care is to maintain the elderly's current living capacity and delay ageing so they can enjoy a comfortable living space and receive professional medical services. The elderly can benefit from a safe and accessible environment and receive services through community workers or community support, and their satisfaction with the environment is conducive to their participation in social activities and hobbies, resulting in dependence on the environment. Lee et al. [13] argued that psychological brand commitment can affect individuals' psychological perception and can thus be interpreted as an early influence on loyalty behaviour [14], which refers to repeated purchases of the same brand by the same individual over time [15]. The relationship between brand attachment and trust in the elderly and the increasing demand for high-quality goods and services lead to a positive relationship between elderly satisfaction and consumer loyalty. A positive brand image can enhance customer loyalty $[16,17]$ because if an individual trusts a brand, then he or she may commit to the brand [18]. Most elderly consumers' choice to live in a care environment depends on whether the living environment can meet their physical and physiological needs, i.e., whether it can improve their quality of life.

According to SST [19], individuals' attention, memory, decision-making, and emotional experience are affected by time perception, and their subjective perceptions are associated with motivation, cognition, emotion, and mood. The elderly see that they are ageing and know that their remaining time is becoming increasingly limited; therefore, they tend to prefer and invest more in meaningful goals driven by emotional cognition [20]. Therefore, in the formation and development of brand value, it is necessary to understand whether brand value can bring high value to the related subject or enable the brand to gain a stronger, more stable and more unique competitive advantage through brand extension [21,22]. In addition, during brand extension, whether brand valuere flects the comprehensive value of the corporate group and the functional and emotional values of consumers requires investigation. Thus, in this study, we develop a model that confirms that housing choice among retired people can be the result of the brand attachment process.

\section{Hypothesis Development}

First, as the basis of the research model, we review the literature regarding self-congruence, partner quality, trust and brand commitment, and brand attachment and study whether brand attachment can be extended to related enterprises within the same brand [23]. Furthermore, we also examine whether brand attachment has a mediating effect on trust and living intention (see Table 1). 
Table 1. Construct definitions.

\begin{tabular}{|c|c|c|}
\hline Construct & Definition & Source \\
\hline Self-congruence & $\begin{array}{l}\text { Self-congruence reflects the connection between consumer } \\
\text { self-awareness and brand image. If a consumer compares his/her } \\
\text { self-awareness with the brand image, self-congruence arises and if a } \\
\text { brand is closely related to self-awareness, it is more likely to be } \\
\text { considered trustworthy by the consumer [8]. }\end{array}$ & [24] \\
\hline Partner quality & $\begin{array}{l}\text { Partner quality refers to the assessment of merchandise purchased (or } \\
\text { used) by consumers and the relationship between consumers and the } \\
\text { brand. In communication with consumers, the timeliness of feedback } \\
\text { promotes the consumer-brand relationship, while strengthening brand } \\
\text { trust [25]. }\end{array}$ & {$[26,27]$} \\
\hline Trust & $\begin{array}{l}\text { Brand trust enables consumers to perceive whether a brand is honest, } \\
\text { safe, and trustworthy. If individuals perceive trust in a relationship, } \\
\text { then they are more likely to engage in the relationship, assuming that } \\
\text { consumers with high trust tend to commit to the brand [28]. A brand } \\
\text { trust may also stimulate consumer participation. }\end{array}$ & [29] \\
\hline Brand commitment & $\begin{array}{l}\text { Brand commitment is defined as the emotional perception of the desire } \\
\text { to maintain a useful relationship [30], i.e., consumers strongly desire to } \\
\text { maintain their relationship with the brand, and their emotional } \\
\text { commitment to the brand may affect their participation in social } \\
\text { networks and their opinions [31]. We can assume that if consumers like } \\
\text { a brand, they tend to maintain a relationship with the brand by } \\
\text { participating through various communication technologies. }\end{array}$ & [32] \\
\hline Living intention & $\begin{array}{l}\text { According to purchase intention theory [33], the theory of reasoned } \\
\text { action [34] and the theory of planned behaviour (TPB) [35], consumer } \\
\text { attitude directly affects behavioural intentions. Purchase intention is } \\
\text { interpreted as the willingness of consumers to buy a certain product at a } \\
\text { specific time or under specific circumstances. Therefore, in this study, } \\
\text { we examine whether consumers' choice of a retirement community } \\
\text { represents their living intention. }\end{array}$ & {$[36,37]$} \\
\hline Brand attachment & $\begin{array}{l}\text { Brand attachment links the brand and individuals [7]. In terms of brand } \\
\text { image, this linkage connects the brand with the consumer's self-image. } \\
\text { When the brand satisfies and enriches consumers and enables consumer } \\
\text { self-development, brand attachment emerges [7]. The closer the link } \\
\text { between a brand and consumers, the more self-expression the brand } \\
\text { provides for consumers [38], and thus, the stronger consumer } \\
\text { attachment to the brand is. }\end{array}$ & [39] \\
\hline
\end{tabular}

\subsection{Self-Congruence}

Self-congruence is the connection between elderly consumers' self-awareness and brand image. It is expected that elderly consumers generate self-congruence based on brand image by comparing their self-image with the brand image. If elderly consumers have already made a decision or have developed a close relationship with the brand, a high degree of trust is generated [40]. Partner quality determines consumer response to the brand, which becomes increasingly more important as consumers age; therefore, elderly consumers are particularly concerned about high-quality brands. The same is true for trust. For elderly consumers, partner quality is often highly important $[19,41]$. The strong association between self-congruence and brand can affect brand commitment among elderly consumers [42]. Therefore, to examine whether the brand image of the corporate group can be extended to the retirement community and thus generate in the elderly a representation consistent with their self-image and brand trust in the retirement community, we propose the following hypotheses (see Figure 1): 


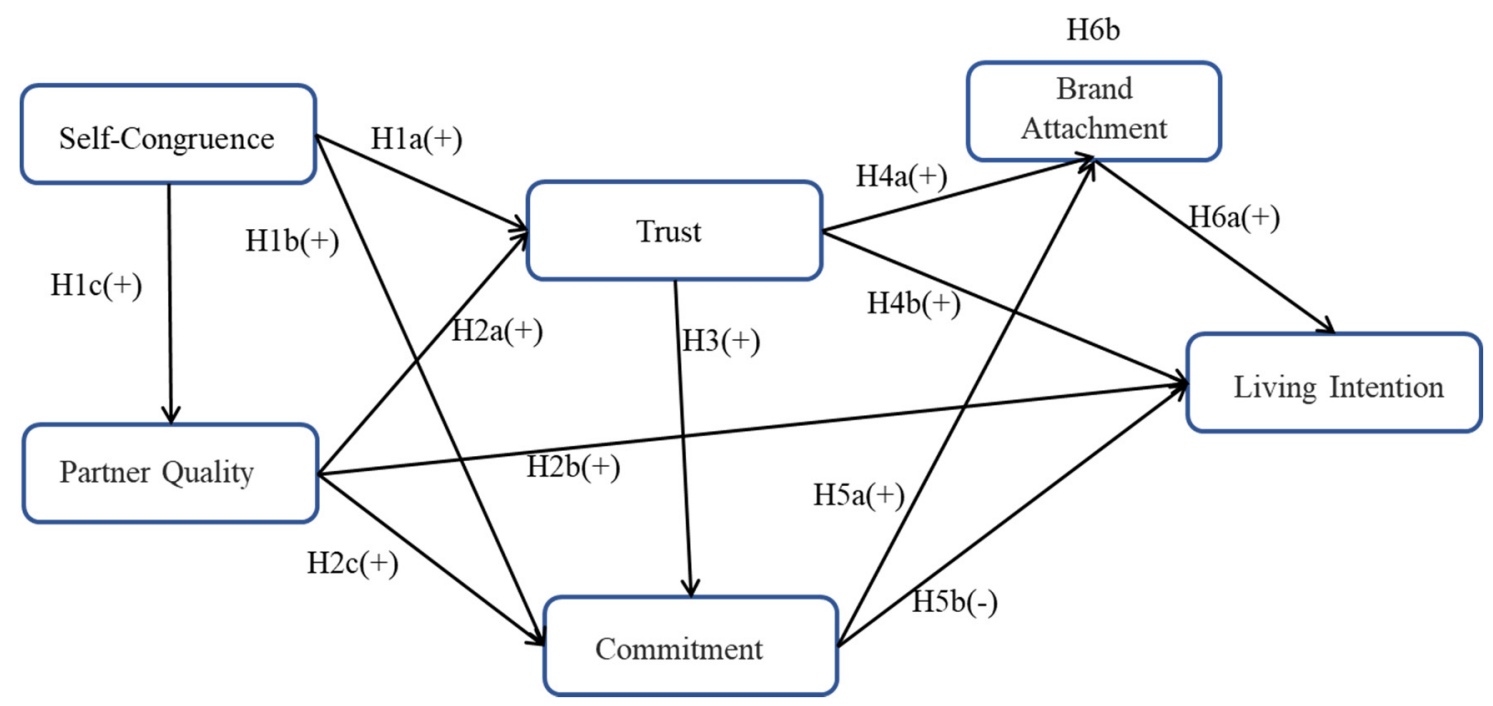

Figure 1. Research framework.

Hypothesis 1 (H1a). The consistency between the corporate group brand image and the retirement community brand image and residents' self-image is positively correlated with brand trust in the retirement community.

Hypothesis 1 (H1b). The consistency between the corporate group brand image and the retirement community brand image and residents' self-image is positively correlated with brand attachment to the retirement community.

Hypothesis 1 (H1c). The consistency between the corporate group brand image and the retirement community brand image and residents' self-image is positively correlated with partner quality for the retirement community.

\subsection{Partner Quality}

Partner quality means that the elderly have confidence in the brand and believe that the brand is reliable [43]. Care and understanding in the partner quality relationship can increase interpersonal trust [40]. When the industry demonstrates understanding of elderly consumers' needs through recognition, brand care and listening, this promotes a relationship between the elderly and the brand and strengthens brand trust [25]. The partner quality of the service team at the retirement community based on the perceptions of the general public and residents. Thus, we propose the following hypotheses:

Hypothesis 2 (H2a). The retirement community includes the service team, and the partner quality between the residents of the retirement community and the retirement community itself is positively correlated with brand trust.

Hypothesis $\mathbf{2}(\mathbf{H} \mathbf{2} \mathbf{b})$. The retirement community includes the service team, and the partner quality between the residents of the retirement community and the retirement community itself is positively correlated with living intention.

Hypothesis 2 (H2c). The retirement community includes the service team, and the partner quality between the residents of the retirement community and the retirement community itself is positively correlated with brand commitment. 


\subsection{Trust and Brand Commitment}

Trust plays an important role in establishing long-term relationships in the business environment [32] and is also an important factor that determines brand commitment. Elderly consumers tend to focus on products they chose in the past [44] and do not seek alternative products unless they feel dissatisfied with the product brand [45]. They do not change their commitment simply based on mood [46]; therefore, the judgment derived from trust is highly important, and brand trust can strongly influence the development of brand commitment. Elderly consumers with a high level of trust tend to have brand commitment, and brand trust may also stimulate consumer participation behaviour. Based on their own experiences or those of relatives, consumers tend to generate various levels of trust. To examine whether experience with the corporate group or the brand value accumulated over time by the team, under the concept of brand extension, can generate trust in, brand commitment to and brand attachment to the corporate group brand image, we propose the following hypotheses:

Hypothesis 3 (H3). Residents' brand trust in the retirement community, which is an extension of brand trust in the corporate group, is positively correlated with brand commitment.

Hypothesis 4 (H4a). Residents' brand trust in the retirement community, which is an extension of brand trust in the corporate group, is positively correlated with brand attachment.

Hypothesis $4 \mathbf{~ ( H 4 b ) . ~ R e s i d e n t s ' ~ b r a n d ~ t r u s t ~ i n ~ t h e ~ r e t i r e m e n t ~ c o m m u n i t y , ~ w h i c h ~ i s ~ a n ~ e x t e n s i o n ~ o f ~ b r a n d ~ t r u s t ~}$ in the corporate group, is positively correlated with living intention.

Hypothesis 5 (H5a). Residents' brand commitment to the retirement community, which is an extension of brand trust in the corporate group, is positively correlated with brand identity/attachment.

Hypothesis $\mathbf{5}$ (H5b). Residents' brand commitment to the retirement community, which is an extension of brand trust in the corporate group, is positively correlated with living intention.

\subsection{Living Intention and Brand Attachment}

In psychological terms, attachment is regarded as the link between individual and specific factors. Although elderly consumers interact with multiple brands, products, and services throughout their lives, they only trust or commit to certain brands and further establish strong attachment relationships $[47,48]$. The stronger their attachment to a brand, the more likely it is that elderly consumers are close to the brand [42]; the interaction between the elderly and the brand can affect brand attachment profoundly [22]. Given the halo effect, individuals infer other characteristics of a cognitive object based on partial impressions of the object; therefore, they start from the parts and expand to gain an overall impression. In some situations, the corporate group brand is associated with a quality service team, and the public wants to receive services from such organisations, if needed. To examine whether the retirement community is recognized as having a quality service team because of the corporate group brand, leading to consumer brand attachment, we propose the following hypotheses:

Hypothesis 6 (H6a). Resident brand attachment to the retirement community, which is an extension of brand trust in the corporate group, is positively correlated with living intention when choosing the retirement community.

Hypothesis 6 (H6b). Resident brand attachment to the retirement community, which is an extension of brand trust in the corporate group, has a mediating effect on brand trust and living intention when choosing the retirement community. 


\section{Methods}

\subsection{Context}

Since being founded in 1973, Chang Gung Memorial Hospital (CGMH), the subject of this case study, has developed a medical brand that is deeply rooted in the minds of the public at all levels in Taiwan. CGMH has brand value, and brand value is a systematic concept of business-consumer interconnection. During brand extension, whether brand value can reflect the comprehensive value of the enterprise and the functional and emotional values of consumers requires investigation. Thus, in this study, we examine whether the brand benefits of CGMH, which focuses on advanced medical treatment, can be extended to brand attachment to Chang Gung Health and Culture Village, which focuses on preventative medicine (Table 2).

Table 2. Operational definitions.

\begin{tabular}{|c|c|}
\hline Construct & Definition \\
\hline Self-congruence & $\begin{array}{l}\text { Creating brand attachment is a key issue in the field of sales, and achieving brand } \\
\text { attachment involves matching the brand image with the consumer's self-image. In this } \\
\text { study, we explore whether the brand image and resident image of the retirement } \\
\text { community (Chang Gung Health and Culture Village) enhances residents' brand } \\
\text { attachment to the retirement community. }\end{array}$ \\
\hline Partner quality & $\begin{array}{l}\text { The service team of the retirement community (Chang Gung Health and Culture Village) } \\
\text { and the service staff in the retirement community belong to community hospitals, special } \\
\text { clinics, and rehabilitation centres, which collaborate with Taoyuan CGMH and Linkou } \\
\text { CGMH to provide convenient access to medical care and therapists, pharmacists, and } \\
\text { physicians, who provide medication counselling and professional medical services. In this } \\
\text { study, we examine whether the high partner quality of the corporate group Chang Gung } \\
\text { Memorial Hospital (CGMH) and the retirement community enhances the trust of residents } \\
\text { in the retirement community and thus their willingness to reside there. }\end{array}$ \\
\hline Trust & $\begin{array}{l}\text { In this study, Chang Gung's brand is based on a group concept that includes medical teams } \\
\text { and nursing care. We examine whether trust in the corporate group (CGMH) can be } \\
\text { extended to trust in the retirement community (Chang Gung Health and Culture Village) } \\
\text { to further improve the living intentions of elderly consumers. }\end{array}$ \\
\hline Brand commitment & $\begin{array}{l}\text { In our case study, CGMH has over } 40 \text { years of history, and the patients who have been } \\
\text { treated at CGMH are gradually entering middle and old age and have various nursing } \\
\text { needs. Because they previously used CGMH, when needing a retirement community, they } \\
\text { may extend their emotional relationship with the CGMH brand and choose Chang Gung } \\
\text { Health and Culture Village. }\end{array}$ \\
\hline Living intention & $\begin{array}{l}\text { Because of ageing, the demand for healthcare by elderly consumers could increase. } \\
\text { After retirement, leisure time also increases. Thus, in addition to their housing needs, } \\
\text { elderly consumers' requirements for health care, recreation, and leisure also increase } \\
\text { accordingly. In this study, the corporate group (CGMH) brand has a wealth of health care } \\
\text { resources, and the retirement community (Chang Gung Health and Culture Village) has } \\
\text { the amenities for physical fitness (sports) as well as for leisure and recreation. We explore } \\
\text { whether such resources can improve the living intention of elderly consumers. }\end{array}$ \\
\hline Brand attachment & $\begin{array}{l}\text { When choosing a retirement community, do previous medical experience at CGMH and } \\
\text { previous living experience at Chang Gung Health and Culture Village, i.e., emotion from } \\
\text { past experiences or brand satisfaction, increase the brand attachment of elderly consumers } \\
\text { to the CGMH brand, thus increasing their living intentions? }\end{array}$ \\
\hline
\end{tabular}

In this case study, CGMH was once voted as the best medical centre in Taiwan and has a good brand image. To examine whether the brand image of CGMH can be extended to Chang Gung Health and Culture Village and thus generate in elderly consumers a representation consistent with their self-image and brand trust for Chang Gung Health and Culture Village, the following hypotheses were constructed based on our proposed research model:

Hypothesis 1 (H1a). The consistency between the brand images of CGMH and Chang Gung Health and Culture Village and residents' self-image is positively correlated with brand trust in Chang Gung Health and Culture Village. 
Hypothesis 1 (H1b). The consistency between the brand images of CGMH and Chang Gung Health and Culture Village and residents' self-image is positively correlated with brand attachment to Chang Gung Health and Culture Village.

Hypothesis 1 (H1c). The consistency between the brand images of CGMH and Chang Gung Health and Culture Village and residents' self-image is positively correlated with partner quality for Chang Gung Health and Culture Village.

In addition, Chang Gung Health and Culture Village includes the medical team (hospital), which ensures a certain level of quality in meeting the needs of residents and maintaining the Chang Gung Health and Culture Village brand. Therefore, the following hypotheses were constructed based on our proposed research model:

Hypothesis 2 (H2a). The service team at Chang Gung Health and Culture Village includes a medical team, and the partner quality between the residents of Chang Gung Health and Culture Village and Chang Gung Health and Culture Village itself is positively correlated with brand trust.

Hypothesis 2 (H2b). The service team at Chang Gung Health and Culture Village includes a medical team, and the partner quality between the residents of Chang Gung Health and Culture Village and Chang Gung Health and Culture Village itself is positively correlated with living intention.

Hypothesis 2 (H2c). The service team at Chang Gung Health and Culture Village includes a medical team, and the partner quality between the residents of Chang Gung Health and Culture Village and Chang Gung Health and Culture Village itself is positively correlated with brand commitment.

Additionally, to examine whether (medical) experience at CGMH or brand value long accumulated by the (medical) team, under the concept of brand extension, can generate trust in, brand commitment to, and brand attachment to the CGMH brand image, the following hypotheses were constructed based on our proposed research model:

Hypothesis 3 (H3). Residents' brand trust in Chang Gung Health and Culture Village, which is an extension of brand trust in CGMH, is positively correlated with brand commitment.

Hypothesis 4 (H4a). Residents' brand trust in Chang Gung Health and Culture Village, which is an extension of brand trust in CGMH, is positively correlated with brand attachment.

Hypothesis 4 (H4b). Residents' brand trust in Chang Gung Health and Culture Village, which is an extension of brand trust in $C G M H$, is positively correlated with living intention.

Hypothesis 5 (H5a). Residents' brand commitment to Chang Gung Health and Culture Village, which is an extension of brand trust in $C G M H$, is positively correlated with brand identity/attachment.

Hypothesis 5 (H5b). Residents' brand commitment to Chang Gung Health and Culture Village, which is an extension of brand trust in CGMH, is positively correlated with living intention.

Finally, the CGMH brand is associated with a quality medical team, and the public wants to receive medical treatment at its facilities, if needed. To examine whether Chang Gung Health and Culture Village is recognized as having a quality team because of the CGMH brand, leading to consumer brand attachment, the following hypotheses were constructed based on our proposed research model: 
Hypothesis 6 (H6a). Resident brand attachment to Chang Gung Health and Culture Village, which is an extension of the CGMH brand, is positively correlated with living intention when choosing Chang Gung Health and Culture Village.

Hypothesis 6 (H6b). Resident brand attachment to Chang Gung Health and Culture Village, which is an extension of the CGMH brand, has a mediating effect on brand trust and living intention when choosing Chang Gung Health and Culture Village.

\subsection{Sampling and Survey Administration}

To measure the constructs proposed in the model, we conducted the following empirical study in which data were collected through a questionnaire survey. The questionnaire was improved based on a construct measurement method, and participants responded to the items using a 5-point Likert scale. All the researchers and participants in this study were protected by the regulations of an ethics committee, and the study was approved by an institutional review board (IRB number 201700360B0C502).

In this study, data were collected at Chang Gung Health and Culture Village, which is an affordable and professional housing retirement community for the elderly in Taiwan and provides a healthy and pleasant living environment for residents, where their physical activity, mental productivity, and quality of life needs are met. The questionnaire survey was administered in the activity hall of Chang Gung Health and Culture Village during interviews with 101 randomly selected residents (age: $57-96$ years old) (see Table 3).

Table 3. Descriptive statistics of the respondents.

\begin{tabular}{cccc}
\hline Measures & Items & Frequency & Percent \\
\hline Gender & Male & 25 & 24.8 \\
$(\mathrm{~N}=101)$ & Female & 76 & 75.2 \\
\hline & $50-59$ & 2 & 2.0 \\
Age & $60-69$ & 8 & 7.9 \\
$(\mathrm{~N}=101)$ & $70-79$ & 43 & 42.6 \\
$(\mathrm{M}=78.81)$ & $80-89$ & 38 & 37.6 \\
& $90-99$ & 8 & 7.9 \\
& Other & 2 & 2.0 \\
\hline & Graduate level & 10 & 9.9 \\
Education & University (4 years) & 44 & 43.6 \\
$(\mathrm{~N}=101)$ & High school & 30 & 29.7 \\
& Junior high school & 10 & 9.9 \\
& Other & 7 & 6.9 \\
\hline
\end{tabular}

\subsection{Instrument Development and Statistical Analysis}

We employed structural equation modelling (SEM) to estimate the coefficient of each direct path and thereby test the hypothesis for each direct effect. We used the statistical package for the social sciences (SPSS) software to analyse the descriptive data and the correlation between constructs and the partial least squares (PLS) method were used to perform confirmatory analysis. We used two-step analysis, i.e., a measurement model and a structural model [49], and tested the internal consistency (i.e., reliability), convergent validity, and discriminant validity. In terms of internal consistency, Smart PLS software provides a reliability measurement, and many studies have demonstrated that Cronbach's alpha can be used as an additional indicator; convergent validity was assessed using the average variance extracted (AVE) and factor loadings, and the discriminant validity was confirmed by performing the AVE test and cross-load examinations [50,51] (see Table 4). We used three indicators to test the reliability of each item: (1) Cronbach's $\alpha$ (whether it was greater than 0.7); (2) composite 
reliability (CR) (whether it was greater than 0.6); (3) AVE (whether it was greater than 0.5). PLS is an SEM method that requires a relatively small sample size [52] and does not require a normal distribution [53]. The PLS-SEM method, including the data distribution, sample size, and indicators accepted in many business disciplines (see Table 5).

Table 4. Internal consistency and correlations across constructs.

\begin{tabular}{ccccccccc}
\hline & AVE & Composite Reliability & BA & CM & LI & PQ & SA & TS \\
\hline BA & 0.602 & 0.881 & 0.832 & & & & & \\
CM & 0.715 & 0.882 & 0.520 & 0.802 & & & & \\
LI & 0.636 & 0.875 & 0.621 & 0.320 & 0.812 & & & \\
PQ & 0.580 & 0.805 & 0.378 & 0.388 & 0.579 & 0.639 & & \\
SA & 0.810 & 0.928 & 0.417 & 0.408 & 0.449 & 0.756 & 0.884 & \\
TS & 0.684 & 0.812 & 0.483 & 0.458 & 0.513 & 0.567 & 0.509 & 0.538 \\
\hline
\end{tabular}

Table 5. Outer loadings and cross-loadings.

\begin{tabular}{lcccccc}
\hline & BA & CM & LI & PQ & SA & TS \\
\hline BA1 & 0.612 & 0.421 & 0.269 & 0.266 & 0.403 & 0.357 \\
BA2 & 0.672 & 0.474 & 0.273 & 0.212 & 0.324 & 0.332 \\
BA4 & 0.838 & 0.369 & 0.552 & 0.380 & 0.370 & 0.421 \\
BA5 & 0.855 & 0.391 & 0.604 & 0.338 & 0.325 & 0.409 \\
BA6 & 0.866 & 0.410 & 0.611 & 0.260 & 0.241 & 0.360 \\
CM1 & 0.382 & 0.752 & 0.186 & 0.203 & 0.210 & 0.301 \\
CM2 & 0.365 & 0.864 & 0.191 & 0.308 & 0.337 & 0.389 \\
CM3 & 0.538 & 0.913 & 0.387 & 0.429 & 0.443 & 0.450 \\
LI1 & 0.417 & 0.219 & 0.731 & 0.488 & 0.402 & 0.226 \\
LI2 & 0.318 & 0.114 & 0.790 & 0.363 & 0.179 & 0.251 \\
LI3 & 0.614 & 0.281 & 0.834 & 0.403 & 0.331 & 0.532 \\
LI4 & 0.559 & 0.350 & 0.831 & 0.565 & 0.467 & 0.535 \\
PQ1 & 0.356 & 0.259 & 0.529 & 0.809 & 0.709 & 0.389 \\
PQ2 & 0.162 & 0.127 & 0.394 & 0.769 & 0.537 & 0.379 \\
PQ3 & 0.322 & 0.480 & 0.384 & 0.704 & 0.463 & 0.525 \\
SA1 & 0.418 & 0.438 & 0.392 & 0.694 & 0.923 & 0.565 \\
SA2 & 0.298 & 0.294 & 0.342 & 0.596 & 0.887 & 0.364 \\
SA3 & 0.393 & 0.353 & 0.471 & 0.739 & 0.890 & 0.421 \\
TS1 & 0.377 & 0.343 & 0.470 & 0.548 & 0.487 & 0.846 \\
TS2 & 0.426 & 0.419 & 0.374 & 0.383 & 0.349 & 0.808 \\
\hline
\end{tabular}

\section{Results}

In this study, we used PLS-SEM analysis in which 5000 bootstrapping samples were used for t-tests and standard error analysis, to test the significance of the hypothetical relationship between the variables [54,55]. Similar to that in multiple regression, the R2 statistic here refers to the variation explained by related latent variables. Figure 2 summarizes the conceptual model, path coefficient, and significance level through R2. This study confirms the initial constructs in the model. Self-congruence had a significant positive correlation with partner quality $(B=0.756, p<0.001)$. The direct effect of partner quality on trust was significant and positive $(B=0.426, p<0.01)$, while that of partner quality on living intention was also significant and positive $(B=0.375, p<0.001)$. The direct effect of trust on brand commitment was significant and positive $(B=0.326, p<0.01)$, as was that of commitment on brand attachment $(B=0.310, p<0.05)$ and that of brand attachment on living intention $(B=0.377, p<0.01)$. The above results are all statistically significant. The data analysis results from this study do not support $\mathrm{H} 1 \mathrm{a}(\mathrm{B}=0.187, p=1.224), \mathrm{H} 1 \mathrm{~b}(\mathrm{~B}=0.206, p=1.256), \mathrm{H} 2 \mathrm{c}(\mathrm{B}=0.047, p=0.281)$, $\mathrm{H} 4 \mathrm{~b}(B=0.127, p=1.037)$, or H5b $(B=-0.138, p=1.391)$ and show that gender, education, children, and marriage are not correlated with living intention. 


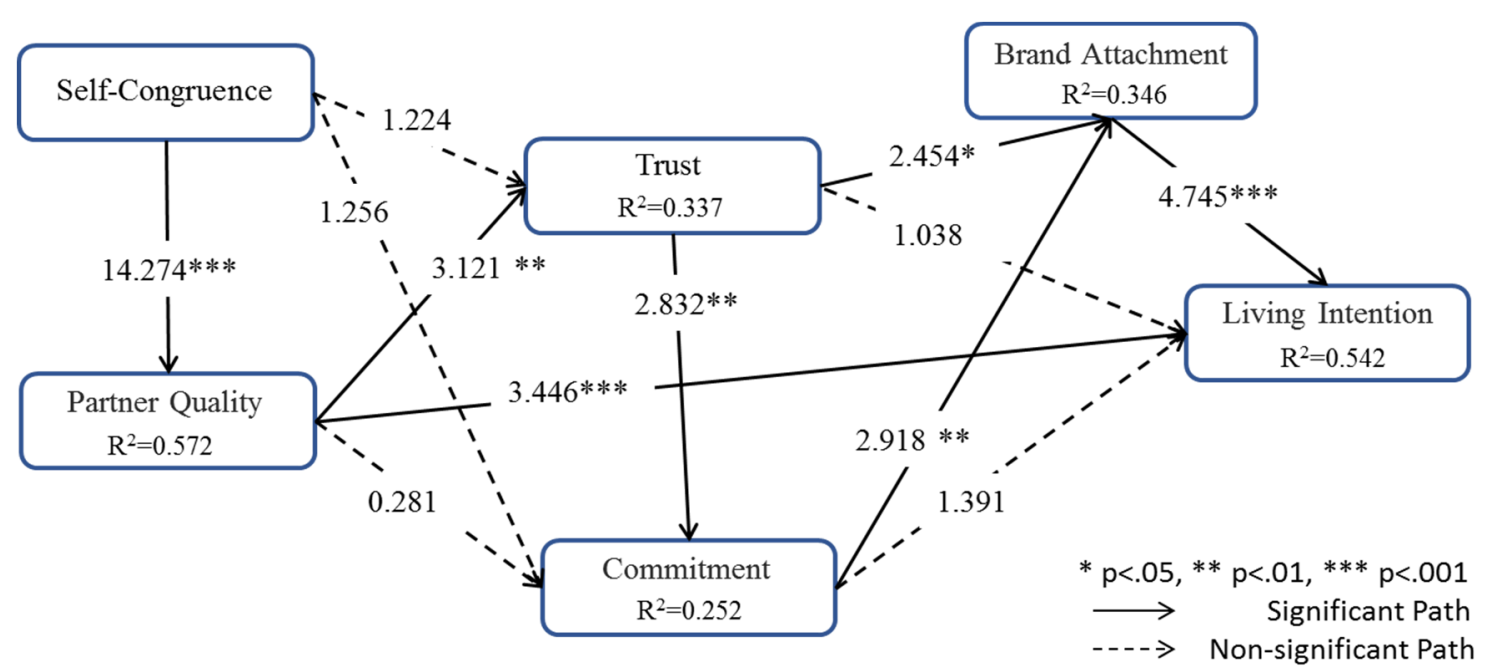

Figure 2. Structural model with path coefficients.

The results of the comparison of self-congruence and brand image showed that trust and brand commitment did not affect the connection between the self-awareness of the residents of Chang Gung Health and Culture Village and brand image, while self-congruence and partner quality had a significant impact, indicating that the residents of Chang Gung Health and Culture Village had a high degree of trust regarding the high partner quality of CGMH and Chang Gung Health and Culture Village. Trust had a significant impact on brand commitment but not on living intention, indicating that trust in CGMH cannot be extended to trust in Chang Gung Health and Culture Village to increase living intention. Commitment supported brand attachment but not living intention; therefore, the residents' medical experience at CGMH did not extend to an emotional relationship with the CGMH brand and thus lead them to choose to live at Chang Gung Health and Culture Village. However, brand attachment supported living intention, indicating that past experiences or satisfaction with the brand increased residents' attachment to the CGMH brand and thus their living intention.

Table 6 shows the hypothesis test results. Regarding Hypothesis 1, the brand image of Chang Gung Health and Culture Village was consistent with residents' self-image; however, it was not positively correlated with brand trust in and brand commitment to Chang Gung Health and Culture Village and only significantly impacted the partner quality for Chang Gung Health and Culture Village, indicating that the residents of Chang Gung Health and Culture Village gained trust in Chang Gung Health and Culture Village through partner quality.

Regarding Hypothesis 2, partner quality was significantly positively correlated with living intention, indicating that living intention was affected by partner quality (e.g., CGMH) and that the elderly had a high level of trust in CGMH, which further influenced their living intention. However, possibly due to differences in the management systems, the residents of Chang Gung Health and Culture Village did not have brand commitment through partner quality.

Regarding Hypotheses 3-5, because of brand trust in CGMH, residents' extension of brand trust to Chang Gung Health and Culture Village was positively correlated with brand commitment and brand attachment; however, factors other than trust and brand commitment had a greater effect on residents' living intention. Previous studies have shown that elderly consumers' brand commitment does not change with mood [46] and that brand trust may also stimulate consumer participation. During the interviews, we found that due to their uncertainty regarding life and a lack of control over their future life, health, etc., elderly consumers' brand trust and brand commitment were not sufficient to affect living intention; therefore, brand trust and brand commitment had no effect on living intention. In the future, we can further examine the effect of elderly consumers' financial management on living intention. 
Table 6. Hypothesis test results.

\begin{tabular}{|c|c|c|c|c|c|c|c|}
\hline & $\begin{array}{c}\text { Original } \\
\text { Sample (O) }\end{array}$ & $\begin{array}{c}\text { Sample } \\
\text { Mean (M) }\end{array}$ & $\begin{array}{c}\text { Standard Deviation } \\
\text { (STDEV) }\end{array}$ & $\begin{array}{l}\text { Standard Error } \\
\text { (STERR) }\end{array}$ & $\begin{array}{l}\text { T Statistics } \\
\text { (|O/STERR|) }\end{array}$ & $p$ Value & Support \\
\hline $\mathrm{BA} \rightarrow \mathrm{LI}$ & 0.490 & 0.495 & 0.103 & 0.103 & 4.745 & $* * *$ & Yes \\
\hline $\mathrm{CM} \rightarrow \mathrm{BA}$ & 0.378 & 0.390 & 0.129 & 0.129 & 2.918 & $* *$ & Yes \\
\hline $\mathrm{CM} \rightarrow \mathrm{LI}$ & -0.138 & -0.139 & 0.099 & 0.099 & 1.391 & & No \\
\hline $\mathrm{PQ} \rightarrow \mathrm{CM}$ & 0.047 & 0.052 & 0.168 & 0.168 & 0.281 & & No \\
\hline$\hat{\mathrm{PQ}} \rightarrow \mathrm{LI}$ & 0.375 & 0.377 & 0.109 & 0.109 & 3.446 & $* * *$ & Yes \\
\hline $\mathrm{PQ} \rightarrow \mathrm{TS}$ & 0.426 & 0.433 & 0.137 & 0.137 & 3.121 & $* *$ & Yes \\
\hline$\widehat{\mathrm{SA}} \rightarrow \mathrm{CM}$ & 0.206 & 0.194 & 0.164 & 0.164 & 1.256 & & No \\
\hline $\mathrm{SA} \rightarrow \mathrm{PQ}$ & 0.756 & 0.761 & 0.053 & 0.053 & 14.274 & $* * *$ & Yes \\
\hline $\mathrm{SA} \rightarrow \mathrm{TS}$ & 0.187 & 0.187 & 0.153 & 0.153 & 1.224 & & No \\
\hline $\mathrm{TS} \rightarrow \mathrm{BA}$ & 0.310 & 0.307 & 0.127 & 0.127 & 2.454 & $*$ & Yes \\
\hline $\mathrm{TS} \rightarrow \mathrm{CM}$ & 0.326 & 0.339 & 0.115 & 0.115 & 2.832 & $* *$ & Yes \\
\hline $\mathrm{TS} \rightarrow \mathrm{LI}$ & 0.127 & 0.113 & 0.122 & 0.122 & 1.038 & & No \\
\hline
\end{tabular}

Note: $\mathrm{BA}=$ brand attachment $\mathrm{LI}=$ living intention; $\mathrm{CM}=$ commitment; $\mathrm{PQ}=$ partner quality; $\mathrm{TS}=$ trust; $\mathrm{SA}=$ self-congruence. ${ }^{* * *} p<0.001 ;{ }^{* *} p<0.01 ;{ }^{*} p<0.05$.

Regarding Hypothesis 6, we found that the public's perception of the CGMH brand was that of a high-quality medical team. Because of the CGMH brand, residents' extension of brand attachment to Chang Gung Health and Culture Village was positively correlated with living intention and choosing Chang Gung Health and Culture Village. Furthermore, because of the CGMH brand, this extension had a mediating effect on brand trust and living intention with respect to Chang Gung Health and Culture Village. In 2018, David Goodall, the celebrated Australian botanist and ecologist, opted for euthanasia in Switzerland because although he had lived to the age of 104, his quality of life and physical condition had decreased rapidly, indicating that due to ageing, the elderly become more reliant on medical teams and good nursing care to ensure their quality of life, which affects their living intention.

\section{Discussion}

\subsection{Main Findings and Contributions}

From the perspective of brand attachment, this study investigates whether the living intention of elderly consumers is affected by brand image, high partner quality, brand trust and commitment, and brand emotional relationships when choosing a retirement community. We developed a model to confirm that elderly consumers' choice of a retirement community may be the outcome of the brand attachment process. Past studies inferred that self-congruence and partner quality have a positive impact on elderly consumers' brand trust and commitment. However, interview data from this study showed that self-congruence and partner quality did not have a significant impact on this group's brand trust and commitment, likely because when choosing their last residence, unlike when buying general consumer products, elderly consumers attach more importance to nursing care brands, which in turn affects their living intention. Furthermore, in general, gender, education, children, and marriage may play a significant regulatory role, but in this study, we did not find that these factors had any correlation, likely because of various factors, such as economic independence and awareness of self-determination when choosing a retirement community. In contrast, partner quality exerted a strong effect on elderly people's trust and brand commitment. We found that brand attachment influenced trust and living intention, and the data showed that when choosing a retirement community, elderly consumers behaved differently than when buying general merchandise. We believe the findings from this study have important implications for theory and practice.

\subsection{Theoretical Implications}

This study mainly contributes to the existing literature in three respects. First, we expanded the research on partner quality by examining elderly consumers' living intention from the perspective of brand trust and commitment processes. Participation has been the focus of marketing research [56]; however, the present study examined the relationship between brand trust and commitment and 
partner quality. Thus, based on elderly consumers' actual needs, we performed an empirical study on this group's living intention. According to marketing theory, trust and brand commitment are important factors for consumer brand attachment, while partner quality is an influential factor when making purchasing decisions. In this study, we demonstrated the differences by clarifying elderly consumers' intentions. Therefore, the results help to clarify elderly consumers' behaviour in residential environments (i.e., living intention) in detail. Brand awareness and reward activities affect brand image, brand attachment, and brand evaluation, while brand image directly affects brand attachment [57]. Marketing mechanisms can increase brand popularity, and brand users can amplify a brand and draw the attention from brand followers, indicating that influential users can have effects on others with respect to spreading brand content. After obtaining such information, companies can improve their products, gain brand recommendations, improve brand awareness and brand image, find new customers, and even cater to specific groups. Brand attachment can help predict elderly consumers' actual living intention and their dependence on a brand to meet their needs [7], which is a different field of study and affects this group's living intention when choosing a residence through brand dependence. The findings of this study are consistent with those of several recent studies showing that users with brand influence can increase brand awareness and recommendations, which may have long-term effects on potential buyers [58]; brands and consumers sharing similar characteristics can facilitate the formation of an emotional connection between the brand and consumers, and brand attachment may have a positive impact on people's behavioural responses to the brand, thus creating favourable business results [59].

Third, previous studies showed that consumer purchase behaviour is driven by interest and that the higher the degree of consistency is between consumer self-image and product image, the higher the probability that consumers will purchase the product [60]. However, in this study, we found that when choosing a retirement community, it is not enough for elderly consumers to perceive consistency between their self-image and the product image; rather, they must understand the true effect of the brand image. Brand assets are "the marketing effects uniquely attributable to the brand" [61]. In other words, the strength of the brand determines the customer's mentality [62] and affects consumer decision-making [63]. In this study, we found that the credibility of a retirement community as perceived by elderly consumers can be affected by the brand of the same company and partner quality. In this case, there are connections between the partners, and the brand and partner quality are mutually beneficial. When elderly consumers make decisions regarding living intention, economic efficiency is crucial and even drives purchase intent because trust in past assessment is based on the brand credibility that has been established based on past experiences or knowledge of the brand. Partner quality combined with knowledge, skills, resources, and experience strengthens the partnership. In the future, we need to further study changes in managing partners and coordination of quality improvements.

\subsection{Practical Implications}

This research also has practical significance. First, the data analysis results showed that elderly consumers do not care whether the brand image of a retirement community is similar to their self-image and that they exhibit brand attachment because of brand trust. Partner quality is an assessment of the brand relationship, and the brand image of the same company can enhance partner quality, which can promote the development of brand relations and strengthen brand trust [25]. Brand trust through partner quality can directly affect living intention, because brand trust and commitment enable elderly consumers to have brand attachment. The effort by a brand to maintain its relationship with its elderly consumers can affect living intention; therefore, the retirement community should demonstrate interest in and understanding of this consumer group and improve the quality of life of the elderly using partner quality to meet their needs with higher service quality.

Another practical implication is related to the discovery that gender, education, children, and marriage are not correlated with living intention. Previously, these four factors were thought to significantly influence living intention. However, in this study, we found that elderly people attach 
different levels of importance to living intention, which means that as social and family relationships vary, elderly consumers' emphasis on living intention also shifts and that they are paying more attention to personal finances; the needs for comprehensive nursing care, quality of life, and dignity continuously affect the elderly's brand attachment and living intention, and they want to maintain a positive relationship with their retirement community, which is impacted by partner quality and indirectly affects their intention.

\subsection{Research Limitations and Future Research Directions}

In this study, we studied a single retirement community in Taiwan. In future studies, we may consider expanding to populations in other countries to increase the universality of the conclusions. This research was conducted in Taiwan, and the results could be affected by regional culture. Currently, elderly people no longer merely emphasize the importance of nursing care but attach great importance to quality of life in old age, which highlights the importance of the choice of a retirement community as well as quality of life. In future studies, we can examine the effect of the Internet and artificial intelligence (AI) technology on elderly healthcare. Previous studies have shown that elderly individuals' resources and the Internet have become very important (e.g., as a resource for lifelong learning) [64]. An extended study on Internet use among long-term residents in a retirement community could be combined with brand attachment to investigate associations and correlations. Ambient assisted living (AAL) provides innovative ways to respond to the challenge of an ageing population and provides good quality of life, while addressing the ever-changing needs of the elderly [65]. In this regard, we can conduct more practical studies considering the elderly's healthcare needs and expand this study to other cultures, which is very important for theoretical constructs. Living intention can be affected by many factors, and it could be interesting to examine whether these factors differ with the latest advances in modern science and technology, which is expected to further deepen our understanding of elderly consumers' intention in choosing a retirement community. In addition, future research may expend to branding in gerontology. This may include testing the relevance of new concepts, such as product-brand crossover [66], to show how brands can evolve and follow consumers throughout their consumption life cycle, from young to middle age to older adulthood.

\section{Conclusions}

Philip Kotler, a marketing management expert, said that when people buy goods, they do not want to acquire new habits but buy a brand of products that they are familiar with and want [67]. A brand is a subjective perception that is accumulated over the years by consumers from user experience, and its essence is a user's inner feelings about the product and the service. In this study, our first goal was to develop a model and to clarify whether the level of consumer identification with the brand, trust, and commitment can extend to brand trust, and we found that self-congruence and partner quality did not affect the elderly consumers' trust and brand commitment when choosing a retirement community but that high partner quality drove living intention. The second goal of this study was to understand how elderly consumers' brand attachment affected their living intention, and we found that trust and brand commitment had a significant impact on brand attachment, but only indirectly. This is inconsistent with the findings in previous studies that elderly consumers' brand attachment and partner quality have a direct impact on living intention, not necessarily through trust and brand commitment. We also found that elderly consumers' living intention was different from that when buying general consumer goods. We hope that the findings of this study can help researchers and managers of this retirement communities better understand how to improve the elderly consumers' brand attachment to further increase their living intention for a retirement community. 
Author Contributions: Conceptualization: T.-H.T., A.M.K.W. and K.C.T.; methodology: T.-H.T. and K.C.T.; validation: T.-H.T., H.-F.L. and K.C.T.; formal analysis: T.-H.T., H.-F.L. and K.C.T.; investigation: T.-H.T., H.-F.L. and K.C.T.; resources: T.-H.T., A.M.K.W. and K.C.T.; data curation: T.-H.T., H.-F.L. and K.C.T.; writing-original draft preparation: T.-H.T., H.-F.L. and K.C.T.; writing-review and editing: T.-H.T., A.M.K.W. and K.C.T.; visualization: H.-F.L. and K.C.T.; supervision: T.-H.T., A.M.K.W. and K.C.T.; funding acquisition: T.-H.T., A.M.K.W. and K.C.T. All authors have read and agreed to the published version of the manuscript.

Funding: The authors disclosed receipt of the following financial support for the research, authorship, and/or publication of this article: This research work was supported in part by the Ministry of Science and Technology of Taiwan, ROC (grant numbers MOST 109-2410-H-027-003-MY2, MOST 108-2410-H-027-024-MY3, MOST 106-2628-H-027-001-MY3 and MOST 108-2622-8-027-007-TM1) and by the Chang Gung Medical Foundation (grant numbers CMRPD3E0373, CMRPG5E0083, CMRPG5F0143 and CMRPD2F0213). The funders had no role in the study design, data collection and analysis, decision to publish, or preparation of the manuscript.

Conflicts of Interest: The authors declare no conflict of interest.

\section{References}

1. Ayalon, L. Transition and Adaptation to the Continuing Care Retirement Community From a Life Course Perspective: Something Old, Something New, and Something Borrowed. J. Appl. Gerontol. 2018, 37, $267-288$. [CrossRef] [PubMed]

2. Van Patten, R.; Lee, E.E.; Graham, S.A.; Depp, C.A.; Kim, H.-C.; Jeste, D.V.; Twamley, E.W. The utility of the timed up-and-go test in predicting cognitive performance: A cross-sectional study of independent living adults in a retirement community. J. Appl. Gerontol. 2019,1,1-11. [CrossRef]

3. Nyffenegger, B.; Krohmer, H.; Hoyer, W.D.; Malaer, L. Service Brand Relationship Quality: Hot or Cold? J. Serv. Res. 2015, 18, 90-106. [CrossRef]

4. Carstensen, L.L. The influence of a sense of time on human development. Science 2006, 312, $1913-1915$. [CrossRef]

5. Malär, L.; Krohmer, H.; Hoyer, W.D.; Nyffenegger, B. Emotional Brand Attachment and Brand Personality: The Relative Importance of the Actual and the Ideal Self. J. Mark. 2011, 75, 35-52. [CrossRef]

6. Sprott, D.; Czellar, S.; Spangenberg, E. The importance of a general measure of brand engagement on market behavior: Development and validation of a scale. J. Mark. Res. 2009, 46, 92-104. [CrossRef]

7. Park, C.W.; Macinnis, D.J.; Priester, J.; Eisingerich, A.B.; Iacobucci, D. Brand attachment and brand attitude strength: Conceptual and empirical differentiation of two critical brand equity drivers. J. Mark. 2010, 74, 1-17. [CrossRef]

8. Jahn, S.; Gaus, H.; Kiessling, T. Trust, Commitment, and Older Women: Exploring Brand Attachment Differences in the Elderly Segment. Psychol. Mark. 2012, 29, 445-457. [CrossRef]

9. Sung, Y.; Choi, S.M. "I won't leave you although you disappoint me": The interplay between satisfaction, investment, and alternatives in determining consumer-brand relationship commitment. Psychol. Mark. 2010, 27, 1050-1073. [CrossRef]

10. House, J.S. Understanding Social Factors and Inequalities in Health: 20th Century Progress and 21st Century Prospects. J. Health Soc. Behav. 2002, 43, 125-142. [CrossRef]

11. Kohlbacher, F.; Chéron, E. Understanding "silver" consumers through cognitive age, health condition, financial status, and personal values: Empirical evidence from the world's most mature market Japan. J. Consum. Behav. 2012, 11, 179-188. [CrossRef]

12. Anikeeff, M.A.; Mueller, G.R. Toward Standardizing Seniors Housing Industry Definitions by Project Type. In Seniors Housing; Anikeeff, M.A., Mueller, G.R., Eds.; Springer: Boston, MA, USA, 1998; pp. 89-108.

13. Lee, J.; Graefe, A.R.; Burns, R.C. Examining the Antecedents of Destination Loyalty in a Forest Setting. Leis. Sci. 2007, 29, 463-481. [CrossRef]

14. Kyle, G.T.; Mowen, A.J.; Tarrant, M. Linking place preferences with place meaning: An examination of the relationship between place motivation and place attachment. J. Environ. Psychol. 2004, 24, 439-454. [CrossRef] 
15. Alexandris, K.; Kouthouris, C.; Meligdis, A. Increasing customers' loyalty in a skiing resort: The contribution of place attachment and service quality. Int. J. Contemp. Hosp. Manag. 2006, 18, 414-425. [CrossRef]

16. Kandampully, J.; Suhartanto, D. Customer loyalty in the hotel industry: The role of customer satisfaction and image. Int. J. Contemp. Hosp. Manag. 2000, 12, 346-351. [CrossRef]

17. Antheunis, M.L.; Valkenburg, P.M.; Peter, J. Getting acquainted through social network sites: Testing a model of online uncertainty reduction and social attraction. Comput. Hum. Behav. 2010, 26, 100-109. [CrossRef]

18. Pitta, D.; Franzak, F.; Fowler, D. A strategic approach to building online customer loyalty: Integrating customer profitability tiers. J. Consum. Mark. 2006, 23, 421-429. [CrossRef]

19. Charles, S.T.; Carstensen, L.L. Social and emotional aging. Annu. Rev. Psychol. 2010, 61, 383-409. [CrossRef]

20. Carstensen, L.L.; Fung, H.H.; Charles, S.T. Socioemotional Selectivity Theory and the Regulation of Emotion in the Second Half of Life. Motiv. Emot. 2003, 27, 103-123. [CrossRef]

21. Sonnier, G.; Ainslie, A. Estimating the value of brand-image associations: The role of general and specific brand image. J. Mark. Res. 2011, 48, 518-531. [CrossRef]

22. Keller, K.L. Building strong brands in a modern marketing communications environment. J. Mark. Commun. 2009, 15, 139-155. [CrossRef]

23. Zhang, J.; Bloemer, J.M.M. The impact of value congruence on consumer-service brand relationships. J. Serv. Res. 2008, 11, 161-178. [CrossRef]

24. Ha, S.; Im, H. Identifying the role of self-congruence on shopping behavior in the context of U.S. shopping malls. Cloth. Text. Res. J. 2012, 30, 87-101. [CrossRef]

25. Munuera-Aleman, J.L.; Delgado-Ballester, E.; Yague-Guillen, M.J. Development and validation of a brand trust scale. Int. J. Mark. Res. 2003, 45, 1-18. [CrossRef]

26. Aaker, J.; Fournier, S.; Adam Brasel, S. When good brands do bad. J. Consum. Res. 2004, 31, 1-16. [CrossRef]

27. Park, J.-W.; Kim, K.-H.; Kim, J. Acceptance of brand extensions: Interactive influences of product category similarity, typicality of claimed benefits, and brand relationship quality. ACR N. Am. Adv. 2002, 29, 190-198.

28. Levin, D.Z.; Cross, R. The strength of weak ties you can trust: The mediating role of trust in effective knowledge transfer. Manag. Sci. 2004, 50, 1477-1490. [CrossRef]

29. Sung, Y.; Kim, J. Effects of brand personality on brand trust and brand affect. Psychol. Mark. 2010, $27,639-661$. [CrossRef]

30. Moorman, C.; Deshpandé, R.; Zaltman, G. Factors affecting trust in market research relationships. J. Mark. 1993, 57, 81-101. [CrossRef]

31. Shang, R.-A.; Chen, Y.-C.; Liao, H.-J. The value of participation in virtual consumer communities on brand loyalty. Internet Res. Electron. Netw. Appl. Policy 2006, 16, 398-418. [CrossRef]

32. Morgan, R.M.; Hunt, S.D. The Commitment-Trust Theory of Relationship Marketing. J. Mark. 1994, 58, $20-38$. [CrossRef]

33. Spears, N.; Singh, S.N. Measuring attitude toward the brand and purchase intentions. J. Curr. Issues Res. Advert. 2004, 26, 53-66. [CrossRef]

34. Fishbein, M.; Ajzen, I. Belief, Attitude, Intention and Behaviour: An Introduction to Theory and Research, 1st ed.; Addison-Wesley: Reading, MA, USA, 1975.

35. Ajzen, I. From Intentions to Actions: A Theory of Planned Behavior. In Action Control: From Cognition to Behavior; Kuhl, J., Beckmann, J., Eds.; Springer: Berlin/Heidelberg, Germany, 1985; pp. 11-39.

36. Coyle, J.R.; Thorson, E. The effects of progressive levels of interactivity and vividness in web marketing sites. J. Advert. 2001, 30, 65-77. [CrossRef]

37. Erkan, I.; Evans, C. The influence of eWOM in social media on consumers' purchase intentions: An extended approach to information adoption. Comput. Hum. Behav. 2016, 61, 47-55. [CrossRef]

38. Kleine, S.; Baker, S. An Integrative Review of Material Possession Attachment. Acad. Mark. Sci. Rev. 2004, 1, $1-29$.

39. Zhou, Z.; Zhang, Q.; Su, C.; Zhou, N. How do brand communities generate brand relationships? Intermediate mechanisms. J. Bus. Res. 2012, 65, 890-895. [CrossRef]

40. Dunn, J.R.; Schweitzer, M.E. Feeling and Believing: The Influence of Emotion on Trust. J. Personal. Soc. Psychol. 2005, 88, 736-748. [CrossRef] 
41. Williams, P.; Drolet, A. Age-Related Differences in Responses to Emotional Advertisements. J. Consum. Res. 2005, 32, 343-354. [CrossRef]

42. Thomson, M.; MacInnis, D.J.; Whan Park, C. The Ties That Bind: Measuring the Strength of Consumers' Emotional Attachments to Brands. J. Consum. Psychol. 2005, 15, 77-91. [CrossRef]

43. Kressmann, F.; Sirgy, M.J.; Herrmann, A.; Huber, F.; Huber, S.; Lee, D.-J. Direct and indirect effects of self-image congruence on brand loyalty. J. Bus. Res. 2006, 59, 955-964. [CrossRef]

44. Lambert-Pandraud, R.; Laurent, G.; Lapersonne, E. Repeat Purchasing of New Automobiles by Older Consumers: Empirical Evidence and Interpretations. J. Mark. 2005, 69, 97-113. [CrossRef]

45. Novak, D.L.; Mather, M. Aging and variety seeking. Psychol Aging 2007, 22, 728-737. [CrossRef] [PubMed]

46. Fung, H.H.; Carstensen, L.L. Sending memorable messages to the old: Age differences in preferences and memory for advertisements. J. Personal. Soc. Psychol. 2003, 85, 163-178. [CrossRef] [PubMed]

47. Schouten, J.W.; McAlexander, J.H. Subcultures of Consumption: An Ethnography of the New Bikers. J. Consum. Res. 1995, 22, 43-61. [CrossRef]

48. Baker, T.L.; Rapp, A.; Meyer, T.; Mullins, R. The role of brand communications on front line service employee beliefs, behaviors, and performance. J. Acad. Mark. Sci. 2014, 42, 642-657. [CrossRef]

49. Hair, J.F.; Anderson, R.E.; Tatham, R.L.; Black, W.C. Multivariate Data Analysis, 8th ed.; Prentice Hall: Upper Saddle River, NJ, USA, 2018; p. 832.

50. Hair, J.F.; Sarstedt, M.; Ringle, C.M.; Mena, J.A. An assessment of the use of partial least squares structural equation modeling in marketing research. J. Acad. Mark. Sci. 2012, 40, 414-433. [CrossRef]

51. Lowry, P.B.; Gaskin, J. Partial least squares (PLS) structural equation modeling (SEM) for building and testing behavioral causal theory: When to choose it and how to use it. IEEE Trans. Prof. Commun. 2014, 57, 123-146. [CrossRef]

52. Marcoulides, G.A.; Saunders, C. Editor's comments: PLS: A silver bullet? MIS Q. 2006, 30, iii-ix. [CrossRef]

53. Chin, W.W.; Marcolin, B.L.; Newsted, P.R. A Partial Least Squares Latent Variable Modeling Approach for Measuring Interaction Effects: Results from a Monte Carlo Simulation Study and an Electronic-Mail Emotion/Adoption Study. Inf. Syst. Res. 2003, 14, 189-217. [CrossRef]

54. Chin, W.W. How to Write Up and Report PLS Analyses. In Handbook of Partial Least Squares: Concepts, Methods and Applications; Esposito Vinzi, V., Chin, W.W., Henseler, J., Wang, H., Eds.; Springer: Berlin/Heidelberg, Germany, 2010; pp. 655-690.

55. Sarstedt, M.; Cheah, J.-H. Partial least squares structural equation modeling using SmartPLS: A software review. J. Mark. Anal. 2019, 7, 196-202. [CrossRef]

56. Zhang, K.Z.K.; Benyoucef, M.; Zhao, S.J. Consumer participation and gender differences on companies' microblogs: A brand attachment process perspective. Comput. Hum. Behav. 2015, 44, 357-368. [CrossRef]

57. Barreda, A.; Okumus, F.; Nusair, K.K.; Bilgihan, A. The Mediating Effect of Virtual Interactivity in Travel-Related Online Social Network Websites. Int. J. Hosp. Tour. Adm. 2016, 17, 147-178. [CrossRef]

58. Hassan Zadeh, A.; Sharda, R. Modeling brand post popularity dynamics in online social networks. Decis. Support Syst. 2014, 65, 59-68. [CrossRef]

59. Pentina, I.; Zhang, L.; Basmanova, O. Antecedents and consequences of trust in a social media brand: A cross-cultural study of Twitter. Comput. Hum. Behav. 2013, 29, 1546-1555. [CrossRef]

60. Ekinci, Y.; Riley, M. An investigation of self-concept: Actual and ideal self-congruence compared in the context of service evaluation. J. Retail. Consum. Serv. 2003, 10, 201-214. [CrossRef]

61. Keller, K.L. Conceptualizing, Measuring, and Managing Customer-Based Brand Equity. J. Mark. 1993, 57, 1-22. [CrossRef]

62. Grassl, W. Strategic Brand Management: Building, Measuring, and Managing Brand Equity. J. Consum. Mark. 2000, 17, 263-272. [CrossRef]

63. Erdem, T.; Swait, J. Brand Credibility, Brand Consideration, and Choice. J. Consum. Res. 2004, 31, $191-198$. [CrossRef]

64. Seifert, A.; Doh, M.; Wahl, H.-W. They also do it: Internet use by older adults living in residential care facilities. Educ. Gerontol. 2017, 43, 451-461. [CrossRef]

65. Stephanie, B.; Claudine, M.; Charisse, B.; Ashley, W.; Mei Lan, F.; Piper, J.; Alex, M.; Louise, N.; Arlene, A.; Andrew, S. Ambient Assisted Living Technologies for Aging Well: A Scoping Review. J. Intell. Syst. 2016, 25, $55-69$. 
66. Lim Weng, M.; Teh, P.-L.; Ahmed Pervaiz, K. How do consumers react to new product brands? Mark. Intell. Plan. 2019, 38, 369-385.

67. Kotler, P.; Zaltman, G. Social Marketing: An Approach to Planned Social Change. J. Mark. 1971, 35, 3-12. [CrossRef] [PubMed] 